\title{
Research on the Construction of Enterprise Performance Evaluation System Based on Balanced Scorecard
}

\author{
Hong $\mathrm{JI}^{1}$, Peiwen $\mathrm{ZHANG}^{2, \mathrm{a}}$,Yunqin ZOU ${ }^{3}$ \\ 1 Jiangxi Normal University Science and Technology College,China \\ 2 Jiangxi Normal University Business College, China \\ 3 Jiangxi Normal University Chemical and Chemical engineering College, China \\ a jxsdjh@vip.sina.com
}

Keywords: balanced scorecard, performance evaluation, construction

\begin{abstract}
In the face of diversification of organizational forms, the traditional performance evaluation system that only focuses on financial indicators and internal indicators is no longer applicable. Now more comprehensive performance is used combining financial and non-financial indicators and internal and external indicators. Evaluation method. This paper uses the basic idea of balanced scorecard to construct a corporate performance evaluation system with balanced scorecard as the core from the four aspects of finance, customer, internal process, learning and development, and raises the status of performance appraisal to the strategic level of the enterprise. Suggestions and opinions on the application of the performance evaluation system.
\end{abstract}

\section{Introduction}

With the development of economic globalization, the traditional performance evaluation system, which focuses on tactical feedback, internal orientation and financial measurement, has too much emphasis on financial performance, neglecting information linked with corporate strategic objectives and business activities, and eliminating the past. The performance evaluation system has become a necessity. In order to adapt to the development of the market, the mastery of competitiveness is the key. In order to meet the requirements of corporate performance evaluation in the new era, the Balanced Scorecard (BSC) is a driving force for measuring the future performance of corporate vision and strategy. It is applicable to both long-term and short-term, tangible and intangible, non-financial and financial performance. Multi-faceted performance appraisal tools came into being.

\section{Basic structure of enterprise performance evaluation system of balanced scorecard}

\subsection{Financial level performance evaluation}

The financial indicators are the traditional performance evaluation indicators often used by enterprises, which can comprehensively reflect the performance of the company. The balanced scorecard also retains the financial indicators. Enterprises can choose the financial indicators that apply to them according to the actual situation, which should mainly reflect the situation of enterprise income, cost control and risk control.

\subsection{Customer level performance evaluation}

As the market becomes more competitive, corporate activities must be customer- and market-oriented, focusing on target customer needs and customer satisfaction. According to the actual situation, enterprises can choose indicators such as market share and customer satisfaction as evaluation indicators at the customer level.

\subsection{Internal business process level performance evaluation}

The internal process is a core part of the balanced scorecard evaluation system, and its analysis helps to improve business processes to reduce costs. In general, the Balanced Scorecard positions 
the evaluation indicators of the company's internal business processes in terms of innovation, management, and after-sales service.

\subsection{Learning and growth level performance evaluation}

In the face of increasingly fierce global competition, companies can only continue to maintain their core competitiveness and respond to the changing external environment by continuously learning and innovating. Therefore, companies must focus on training employees' skills and strengthen investment. Indicators at the learning and growth level include employee satisfaction, information coverage and employee training.

\section{3 . Selection and calculation of financial indicators}

Financial indicators are derived from the calculation of various accounting data, which specify the specific behaviors that the company is expected to take, and then conduct performance evaluations to see if the company actually implements these behaviors, and the companies have taken these actions to bring the company What kind of income. Therefore, the evaluation of this indicator is often associated with profitability.

\subsection{Income increase indicator}

The enterprise income increase index is a relatively important indicator for evaluating the financial performance of an enterprise. It mainly reflects the growth rate of the current period's income in the business activities compared with the previous period. This paper selects the increase rate of sales revenue to reflect the increase in corporate income.

\subsection{Cost Control and Productivity Indicators}

Enterprise cost control and productivity are also a very important indicator for evaluating a company's financial performance. This paper selects the cost and expense ratio and the total labor productivity to reflect the enterprise cost control and productivity.

\subsection{Capital utilization}

Capital utilization has important implications for the evaluation of financial performance of enterprises. To improve the capital utilization rate of enterprises is to produce the same amount of products while using capital reduction or to produce more products with the same capital. The working capital turnover rate can be selected to reflect the capital utilization rate.

\section{Selection and calculation of customer indicators}

With the increasingly fierce market competition, the rights of customers are increasingly valued by business operators. Evaluating business performance from a customer perspective is an important aspect.

\section{1 Market share}

The market share reflects the competitiveness of the company's products in the market. From a horizontal perspective, it can be seen that the position of the company's products in the entire market can be used to determine whether the company is in a leading position in the industry competition. It indicates the size of a certain commodity in a company's marketing, reflecting the degree of control of the market and the degree of customer dependence on the company.

\subsection{Customer Satisfaction}

Customer satisfaction is an important indicator to reflect the success of the customer satisfaction strategy. Only when customer satisfaction is continuously improved can the market share continue to expand. The measurement of customer satisfaction can be reflected in indicators such as new customer acquisition rate and old customer retention rate. 


\section{3 Customer interest rate}

The customer's interest rate is the net profit level that the company has achieved after providing products and services to customers. The customers of the enterprise are old and new, and the old customers who can make profits should be kept, and the profitability of the new customers should be differentiated. For those customers who may be profitable in the future, they should strive for those who are not profitable. Should give up. The customer's interest rate can be reflected by the overall customer interest rate.

\section{Selection and calculation of internal process indicators}

From the perspective of internal processes, the problem that enterprises must solve is how to achieve internal competitive advantages and how to adapt to the external environment. It mainly includes innovation, operation, after-sales service and other processes.

\subsection{Innovation}

In the process of innovation, companies should explore the potential and real-world needs of their customers and then create products and services to meet this demand. This index evaluation reflects the innovation ability of the enterprise, and can set specific indicators such as research and development expense rate and research and development success rate.

\subsection{Management}

The business process is the entire process from receiving customer orders to product services and delivering to customers. In this business process, the performance evaluation reflects the supply and sales of the company's product cost, quality, time and so on.

\subsection{After-sales service}

After-sales service is the final performance evaluation index of the internal operation process of the enterprise. Good sales service and after-sales service are another evaluation standard to maintain the competitive advantage of the enterprise. After-sales service includes the basic core services of the enterprise, the provision of product technology, and the environment of the service place. Such indicators include addressing the repair rate of after-sales products and resolving customer complaints rates.

\section{Selection and calculation of learning and development perspectives}

The development potential of modern enterprises is not only the competition of information, resources and technology, but also the competition of talents. Therefore, it is necessary to train and manage new technologies and new knowledge for managers and employees of enterprises, and establish an effective information system so that enterprises can obtain useful information in time. The company's learning and development capabilities can be evaluated from three aspects: employee attitude, information system capability, and incentive mechanism.

The construction and application of the performance evaluation system with the balanced scorecard as the core can help the enterprise to establish a relatively complete and complete indicator database, so that the performance evaluation of the enterprise is clear and clear.

\section{Conclusion}

Key indicators run through the entire process of balanced scorecard metrics, which solves the problem of corporate performance scoring. In order to better measure and analyze some target values and indicator values, verify the causal relationship between indicators, so that the target and indicator values can more realistically reflect the goals and strategies, and some advanced performance measurement methods, information systems and technologies can be used. By using Activity-Based Costing, companies can better measure and manage costs; use economic value 
added to measure shareholder profit indicators to better represent shareholders' interests; use analysis in business intelligence systems Function, you can do some hypothesis testing, predictive analysis and related analysis, etc., using the modeling, dashboard, budget planning and information release functions in the BPM system, can effectively track and monitor the implementation of each indicator and project The progress of the situation.

\section{Acknowledgement}

This paper is one of the research results of The Construction Evaluation Model and Analysis of Influencing Factors of Enterprise Group Performance under Strategic Orientation in The Research Project of the Science and Technology of Jiangxi Provincial Department of Education.

\section{References}

[1] Fenghuo Technology: Strategic Performance Management System with Comprehensive Budget as the Core [J]. Xia Cunhai, Wu Haibo, Li Hongtao, Wang Hua. Financial Supervision. 2018(04)

[2] Research on Performance Evaluation System Based on Enterprise Strategy-Taking Company as an Example [J]. Xu Jinye, Yang Wei, Xu Yuqin. Friends of Accounting. 2018(06)

[3] Reconstruction of A company's strategic performance evaluation system based on BSC[J]. Xu Guanghua, Shao Yeqiu.Friends of Accounting. 2018(01)

[4] Construction and implementation of construction enterprise performance evaluation system based on balanced scorecard[J]. Chen Zhenhong, Yu Wenguo, Wang Yiwen, Xu Lijiang, Hu Jianlong, Fang Yongwei. Finance and Accounting. 2017(14) 